\title{
Investigations of passive wing technologies for load reduction
}

\author{
W. R. Krüger ${ }^{1}$ (D) J. Dillinger ${ }^{1} \cdot$ R. De Breuker ${ }^{2} \cdot$ K. Haydn ${ }^{3}$
}

Received: 12 June 2018 / Revised: 21 March 2019 / Accepted: 3 April 2019 / Published online: 8 May 2019

(c) The Author(s) 2019

\begin{abstract}
Wings of modern aircraft have to be designed to give optimal response with respect to loads, comfort and performance. An essential part of the wing development is thus a design process which can take all these aspects into consideration. In the "Adaptive Wing" work package of the CleanSky "Smart Fixed Wing Aircraft" project, a multi-fidelity wing design method using aeroelastic tailoring has been developed. In the article, the process is presented in detail. The approach is based on a parametric wing design approach. Both beam models and shell models are derived and optimized in separate optimization environments. Investigations of the use of unbalanced laminates in aeroelastic tailoring are presented, employing the optimization of lamination parameters. The applications are demonstrated on two aircraft configurations, a long range and a short range transport aircraft. Further developments presented in the article include the introduction of CFD-based aerodynamics in the tailoring process, and a process extension to assess the influence of aeroelastic tailoring on fatigue.
\end{abstract}

Keywords Load analysis $\cdot$ Load reduction $\cdot$ Parametric model design $\cdot$ Aeroelastic tailoring

\section{Background}

In the framework of the CleanSky "Smart Fixed Wing Aircraft" (SFWA) project, one field of activity has been the investigation of technologies for loads reduction for transport aircraft. Aim of the work package "Adaptive Wing" in SFWA was to create design processes and solutions for aircraft wings giving optimal response with respect to loads,

This paper will be part of a Special Issue on the EU project Smart Fixed Wing Aircraft.

\section{W. R. Krüger}

Wolf.Krueger@DLR.de

J. Dillinger

Johannes.Dillinger@ DLR.de

R. De Breuker

R.DeBreuker@tudelft.nl

K. Haydn

katharina.haydn@lbf.fraunhofer.de

1 Deutsches Zentrum für Luft- und Raumfahrt, Institut für Aeroelastik, Bunsenstr. 10, 37073 Göttingen, Germany

2 Delft University of Technology, Kluyverweg 1, 2629HS Delft, The Netherlands

3 Fraunhofer-Institut für Betriebsfestigkeit und Systemzuverlässigkeit, Bartningstr. 47, 64289 Darmstadt, Germany comfort and performance. This article presents the work in the field of aeroelastic tailoring performed in the project by the Institute of Aeroelasticity of the German Aerospace Center (DLR), the Aerospace Structures and Materials Group of the Delft University of Technology, and the Fraunhofer Institute for Structural Durability and System Reliability.

The structure of the article mirrors the approach taken in the project. In the first phase, the focus was on the development of key technologies of all partners and the establishment and improvement of cooperation among the partners and in the work package. In this phase, the basic multi-fidelity aeroelastic tailoring process was developed, making use of DLR's parametric modelling process, see Sect. 2 . In the second phase of the project, existing design technologies were matured on a common numerical aircraft platform, the so-called XRF1 model, a long range aircraft configuration provided by Airbus [1, 2], see Sect. 3. The focus of the investigations was on the assessment of the use of unconventional laminates for aeroelastic tailoring and its influence of the resulting wing mass. In the third phase, the developed technologies were applied on a second aircraft, the so-called "new short range" (NSR) concept, see Sect. 4, which was used for extending the aeroelastic tailoring process by the introduction of CFD-based aerodynamics into the process. Finally, an assessment of the influence of 
passive load alleviation schemes on fatigue-relevant loads was performed, see Sect. 5 .

Various forms of load control have been employed in aircraft over the years. Regan [3] lists a number of examples for active manoeuvre and gust control on series aircraft; however, for commercial aircraft it is difficult to obtain technical information concerning the exact implementation of the systems. At DLR, research on active load control was performed on the ATTAS aircraft since the 1990s [4]. A wellknown set of investigations is also the Active Aeroelastic Wing (AAW) flight research program, a joint US Air Force/ NASA program [5]. Recent studies include a gust load alleviation approach using a folding wingtip device [6] and aeroservoelastic investigations on the so-called SUGAR Truss Braced Wing configuration [7]. Livne gives an extensive literature overview on load control in his recent article [8].

The optimization of composite materials used to form the load carrying structure of a wing is a research topic that has been discussed for decades; see for example Starnes Jr et al. [9], where the authors apply an approximation-based optimization to minimize the weight of a wing structure subjected to different combinations of buckling, strength, displacement and twist constraints. Hollowell et al. [10] demonstrate the considerable effects induced by the coupling terms in the bending stiffness matrix by analysing the effect of bending-twist coupling on the aeroelastic behaviour of composites' plates with various symmetric, unbalanced stacking sequences. A valuable survey on aeroelastic tailoring effects as a result of the directional stiffness in orthotropic composites is provided in Shirk et al. [11]. The authors investigate the possible influence of rotated fibre angles on minimum weight, twist, normal modes, flutter and aerodynamic performance for various configurations, reaching from fighter aircraft to forward swept configurations. A general overview on optimization technologies reaching from optimizations on panel level to the aeroelastic optimization of composites in aircraft wings is provided in Vanderplaats et al. [12]. In a more recent work, Leon et al. [13] maximize the flutter eigenfrequency of a composite plate wing with ply angles as design variables, considering symmetric and non-symmetric stackings.

Aeroelastic tailoring studies based on lamination parameters have been attempted previously, though not to the same extent as the previously depicted optimizations comprising discrete stacking sequences. Kameyama et al. [14] use a composite plate wing to demonstrate the influence of lamination parameters on the flutter and divergence characteristics. Minimization of compliance of a variable stiffness slender wing that is represented as a beam is demonstrated in Abdalla et al. [15]. The cross-sectional properties of the beam are parametrized using lamination parameters that define the membrane stiffnesses of the box cross section. Results show that variable stiffness layups can significantly outperform structures comprising constant stiffness. Unbalanced laminates in particular, comprising bending-torsion coupling, lead to the best performance in terms of compliance. A two-level optimization strategy has been proposed by Liu [16]. Allowing for symmetric and unbalanced laminates, a lamination parameter-based weight minimization is performed before applying genetic algorithms for the derivation of stacking sequences. The objective function in the second optimization step comprises a minimization of the square distance of lamination parameters. Dillinger [17] presents an optimization approach for composite aircraft wings based on lamination parameters. The introduction of that publication also gives an extensive overview over the development in the field. Next to those sources mentioned, the already cited article by Livne [5] also contains a section on aeroelastic tailoring.

Both the processes developed on the work, i.e. the multifidelity aeroelastic tailoring process, and the investigations performed, i.e. the assessment of the use of unconventional laminates for aeroelastic tailoring, are considered very significant contributions to the field of aeroelastic tailoring, especially as they have been demonstrated not only on academic applications, but on realistic aircraft configurations based on industrial models. Furthermore, a technology readiness level (TRL [18]) of three and higher could be demonstrated for the wing design process by DLR and TU Delft.

\section{Multi-fidelity aeroelastic tailoring process for passive load alleviation}

\subsection{Approach}

Passive load alleviation can be achieved by using the directional stiffness properties of composite materials to tailor the aeroelastic response of the wing. This results in a large design freedom for the designer, making it a challenge to explore the aeroelastic design space efficiently. Therefore, a multi-fidelity multidisciplinary approach to the optimization of a composite wing structure has been developed in the "Adaptive Wing" work package, which employs a two-step optimization procedure. The first step is the optimization of the wing structure using a low-fidelity nonlinear aeroelastic beam model. The result of this optimization is then used for a more detailed optimization of the wing structure using a shell model coupled to doublet-lattice (DLM) aerodynamics implemented in NASTRAN. A comparison between the beam model and the shell model clearly shows the validity of this approach, thus making it suitable for the optimization of aeroelastically tailored wing box structures. The work was performed in cooperation between the DLR Institute of Aeroelasticity and Delft University of Technology [19, 20]. 
The underlying analysis model is defined on the basis of a parameterized geometry. That way, a convenient process for the investigation of parameter spaces can be set up. The parametric structural design tool employed in the process is ModGen [21], developed at DLR. The tool is capable of generating a parametrized structural representation on the basis of the geometry, which is then processed to a NASTRAN sizing optimization.

Two types of models can be derived. First, the initial ModGen shell model is reduced to a computationally less expensive beam model, on which a pre-sizing optimization is called, see the upper branch of Fig. 1. The optimized skin and spar stiffness is calculated in the form of ABD-matrices, representing stacking sequences. Second, the initial ModGen shell model is transferred into a finite element model, on which a structural optimization with aeroelastic constraints is performed, see the lower branch of Fig. 1. Here, too, the stiffness distribution is optimized in the form of ABD-matrices.

Thus, the designer has several choices, depending on the complexity of the models or the design and analysis task - the multi-fidelity process provides representative beam models for wing structures which can be used for the allocation of meaningful start values for the optimization of complex shell models. However, in many applications, aeroelastic analyses on high aspect ratio wings can be performed with good accuracy on beam models directly. For more complex geometries, wing structures can be designed and optimized based on the more detailed shell models.

The following sections will explain the process in more detail and give application examples.

\subsection{Parametric wing definition}

For the generation of the structural wing model, the tool ModGen was used. ModGen has been specifically developed for the generation of parametric representations of structural and aeroelastic models to be used in aeroelastic analysis and optimization tasks; see for example the application on the so-called FERMAT, a structural model for the CRM configuration [22], or on a forward-swept wing aircraft [23].

Based on a definition of the wing surface, ModGen is capable of generating a finite element shell model within this contour, involving wing skins, spars, ribs and stringers, the latter one being represented by beam elements. The wing surface can either be provided as surfaces in the well-known Initial Graphics Exchange Specification (IGES) format or by sets of airfoil contours and their positions in space. ModGen also provides a DLM model for aerodynamics and a splining model between the structure and DLM grid; see Fig. 2.

Furthermore, mass models considering fuel distributions can be generated. Finally, ModGen provides the required input data for the sizing as an optimization problem, i.e. the design and optimization variables. Optimization can be performed in NASTRAN [24], using SOL 200 for optimization based on the native NASTRAN elements. However, in the aeroelastic tailoring process developed in SFWA and presented here, structural optimization is performed by an optimizer provided by TU Delft.

\subsection{Wing design optimization using fast design methods}

TU Delft has focussed on the passive wing optimization on a beam level. The work was carried out in close collaboration with the DLR Institute of Aeroelasticity. The passive

Fig. 1 Multi-fidelity design process

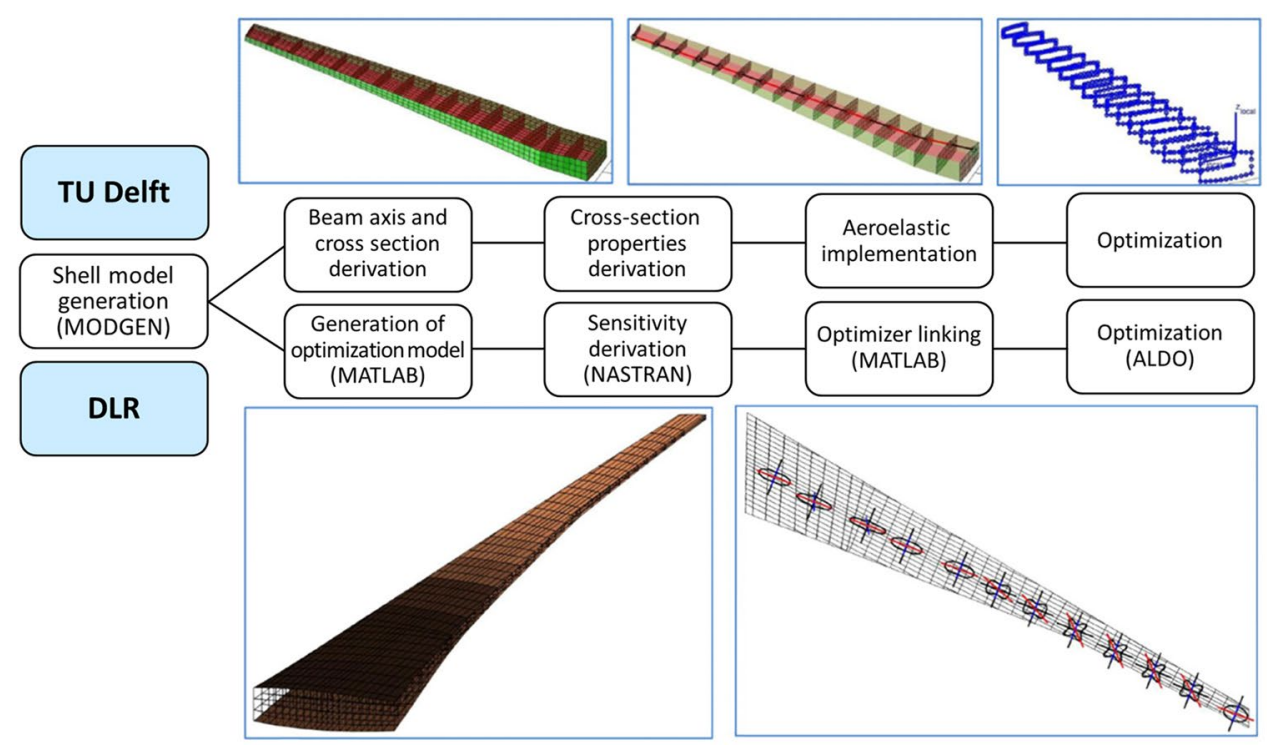



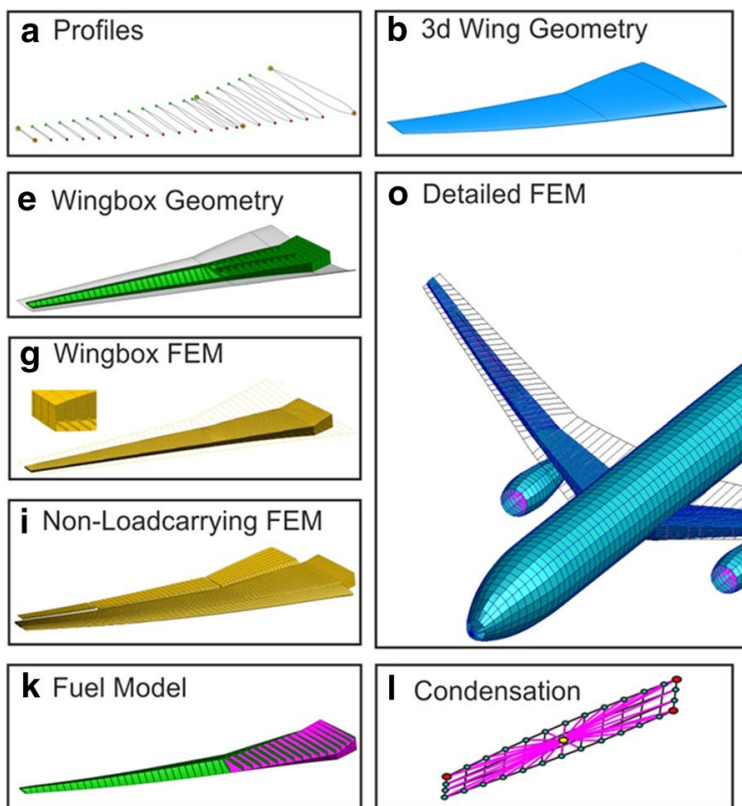

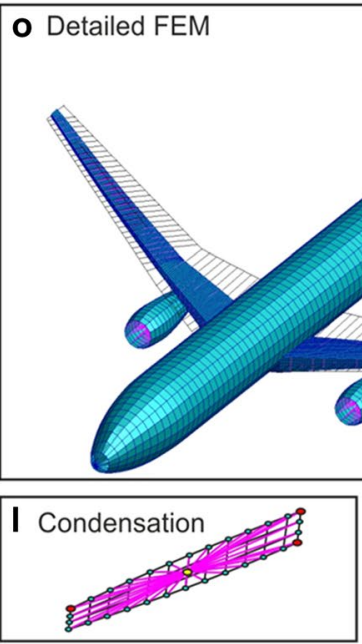

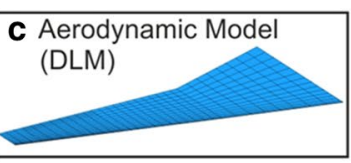

Aerodynamic Model
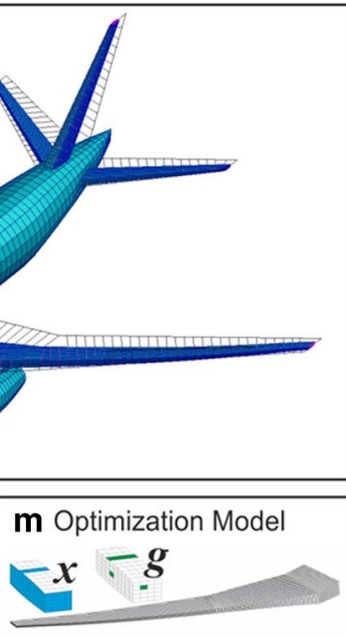
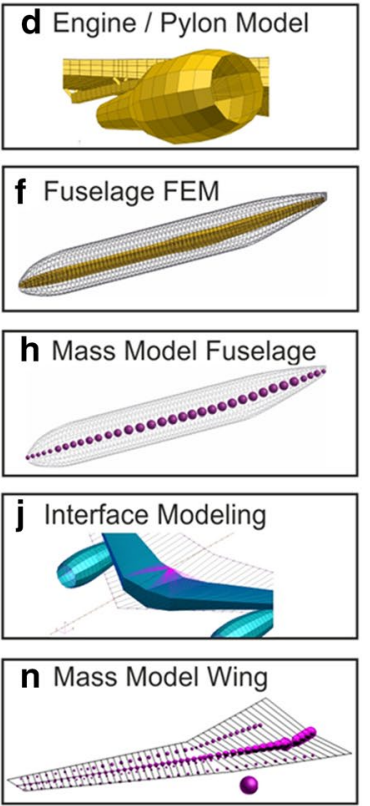

Fig. 2 Model elements created by the parametric ModGen process

loads alleviation was envisioned to be attained by making use of the directional properties of anisotropic composites. The intricate problem of composite wing skin and spar optimization, which inherently is associated with a large number of design variables and constraints, was handled by setting up a multi-fidelity design loop, making up the "upper" branch in Fig. 1.

TU Delft developed a low-fidelity aeroelastic optimization routine which can quickly design a spanwise and chordwise stacking sequence distribution; see [25]. This low-fidelity design can then serve as an initial guess for the DLR medium-fidelity optimization.

The TU Delft low-fidelity aeroelastic optimization strategy consists of the monolithic coupling between a continuous-time unsteady vortex lattice aerodynamic code and a geometrically nonlinear Timoshenko beam code. The structural dynamics are linearized around the static nonlinearly deflected shape. The composite laminates can be varied in chordwise and spanwise direction over the wing in various design zones. The discrete composite stacking sequence discretization is parameterized in a continuous fashion using lamination parameters. This way, gradient-based optimization is realizable, which is an essential ingredient when dealing with an optimization problem of multiple hundreds or thousands of design variables. Using this approach, the wing can be sized for a variety of manoeuvre load cases including constraints such as buckling, strength, divergence, aileron efficiency and flutter. More details of the approach are given in [20].
The methodology was applied to the new-short range (NSR) aircraft, see Sect. 4, and it was shown that anisotropic laminates can reduce the wing structural weight by $30 \%$ as compared to quasi-isotropic composite laminates. A typical result skin thickness for the wing is shown in Fig. 3, left, together with the optimized stiffness distribution, Fig. 3, right. Here, the dark curves indicate the main stiffness direction in a design field, a slender oval representing a unidirectional local stiffness, a rosetta or a square representing a more isotropic local behaviour.

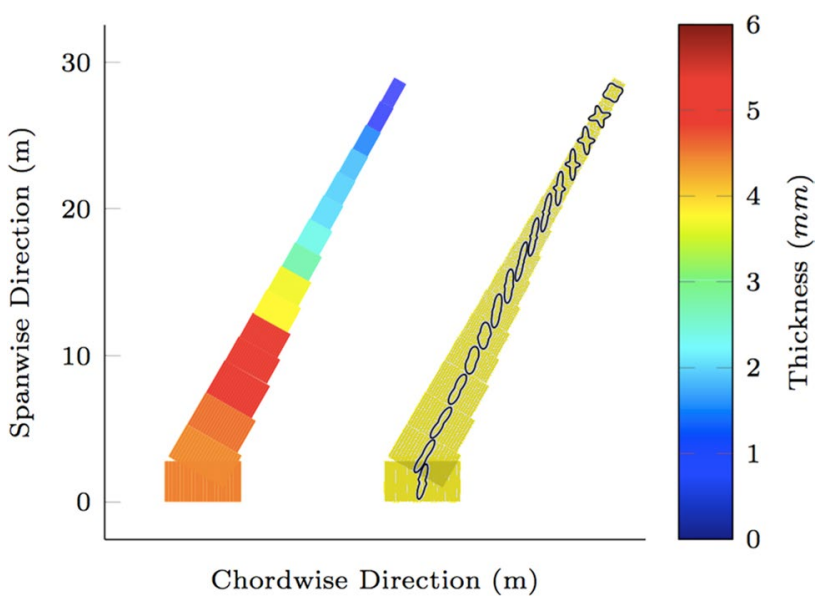

Fig. 3 Results of the fast aeroelastic tailoring design process-local skin thickness (left) and main stiffness direction (right) for design fields 


\subsection{Aeroelastic design and tailoring process for dynamic global finite element models}

For the application of the aeroelastic design process based on the shell model, according to the lower branch of Fig. 1, it is assumed that a basic aircraft design exists. Figure 4 provides an overview of the design loop. The aircraft configuration and global aircraft data form an input to the procedure. For the description of the wing, the basic wing layout and the wing topology should be available. A given basic structural design, material properties, loads envelope, formulation of constraints, non-structural masses and fuel can be included if available, otherwise suitable data are created as part of the wing design process (Fig. 4, "input" step). Based on the input, a wing model is created, with a focus on the parametric structural model (Fig. 4, "model generation" step). The model consists of the structure ("FEM"), a DLM model ("Aero"), and the definition of the design variables ("DVar") for the subsequent optimization step. A preliminary sizing of the wing structure, to get a good starting point for the optimization, is part of the model generation. In the next step (Fig. 4, "sizing and optimization" step), the optimization problem is formulated, and the sizing of the wing structure is performed using optimization of the stiffness distribution according to the requirements; such requirements are usually minimum weight, a prescribed flight shape, minimum static and dynamic loads, as well as required control surface efficiency. The output of the design process can be a separate wing analysis model; however, models for all the components, main wing, empennage and fuselage, can be generated. In that case, a full aircraft model will be assembled from the components ("analysis model"), which is then available for further design studies (Fig. 4, "analysis" step), for example the design of control laws, aeroelastic analysis or more detailed load analyses, e.g. with CFD-based calculations. The results of the latter can be included in the sizing loop, if desired.

A wing optimization in the presence of aeroelastic constraints is often called "aeroelastic tailoring", usually associated with the use of composites, i.e. fibre-reinforced materials. This process is the core of the "sizing and optimization" block of the aeroelastic design loop shown in Fig. 4. The aeroelastic tailoring process is depicted in more detail in Fig. 5. The parameterized wing model which forms the input
Fig. 4 Aeroelastic design process

Fig. 5 Aeroelastic tailoring process
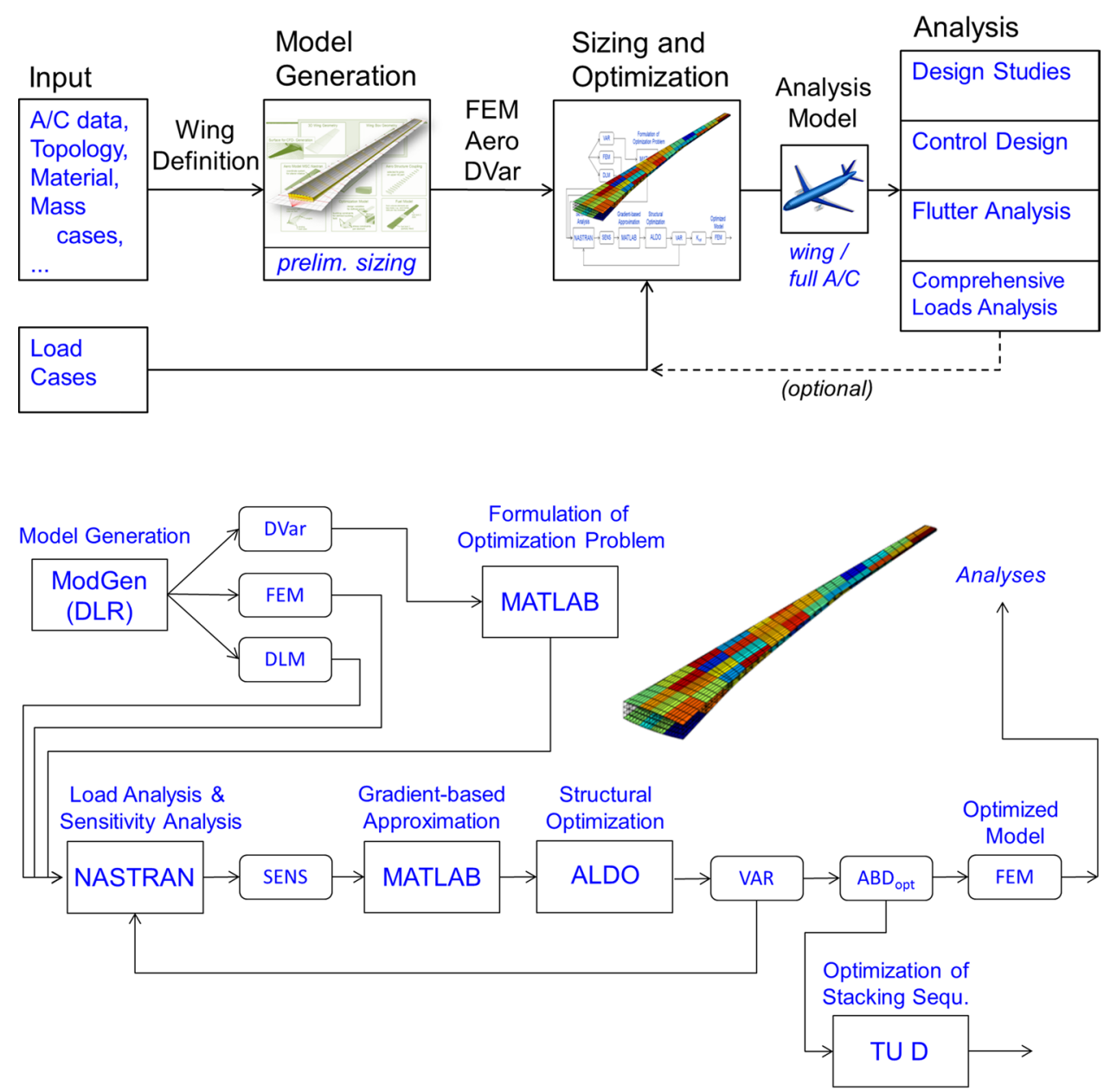
of the tailoring step is taken from the modelling step "model generation" (Fig. 4), i.e. a NASTRAN model including wing structure and mass model ("FEM"), aerodynamic ("DLM") grid and design and optimization variables ("DVar"). The optimization problem is defined in MATLAB [26] and the tailoring loop is started. A number of load cases relevant to the optimization are defined in MSC.NASTRAN. This tool is used both for the load analysis of those cases and for the subsequent generation of the sensitivities of the objective function and responses with respect to the structural design parameters, e.g. stiffness distribution and layout of laminates. Those sensitivities ("SENS") are converted to linear and reciprocal sensitivities with respect to the stiffness matrices. The approximation model ("gradient-based approximation") replaces the actual analysis model in the search of the optimizer for a minimum of the objective function, greatly accelerating the function evaluations required during the optimization. The step "structural optimization" consists of a gradient-based optimization in the TU Delft optimizer ALDO [19], which generates feasible stiffness distributions for the wing structure, described in the form of the so-called ABD-matrices, the stiffness matrix in classical laminate theory [19], along with consideration of their feasible region. Each optimization step results in a new set of design variables ("VAR") that represent the global optimum of the convex approximation subproblem. Convergence is monitored by determining the change in the objective function for subsequent feasible iterations.

The optimization implemented in the process is capable of considering balanced and unbalanced laminates. For all subsequent analyses using the resulting model ("optimized model") described in the following sections of the article, the general formulation (stiffness, mass distribution, " $A B D_{\text {opt }}$ ") was used for the FEM. However, an optimized laminate stacking sequence which represents the optimal $\mathrm{ABD}$-solution (" $\mathrm{ABD}_{\mathrm{opt}}$ ") can be generated in a post-processing step ("optimization of stacking sequ."). A more detailed description of the optimization process can be found in [27]. The process has been used for wings of several aircraft configurations. The applications will be described in the following sections.

\subsection{Process validation: the ICW wing}

The aeroelastic tailoring process was built up and verified using the academic example intermediate complexity wing, ICW, for tools and process development. The ICW is a reference composite wing, which has been examined in several optimization papers [28]. ModGen has been used to generate a finite element model with 32 upper and 32 lower skin shell elements with PSHELL/MAT2 property definition. Design variables are lamination parameters and laminate thicknesses. The design variable sensitivities for specified responses are computed with NASTRAN SOL200 and the sensitivities passed to the optimizer. Stacking sequences of the wing box are extracted, and the stiffness matrices of the box plates calculated. Figure 6, left, shows the layup for an optimization with respect to a required control layout efficiency. The lamination parameters indicate the direction of the main stiffness, $V 1$ and $V 3$ correspond to the $A$ matrix (membrane stiffness) and the parameters $W 1$ and $W 3$ to the $D$ matrix (bending stiffness). The coupling matrix $B$ is zero because a symmetric laminate is chosen. The parameters $V 2, V 4, W 2, W 4$ are also zero because a balanced laminate was regarded. The resulting global stiffness properties were compared to literature results, and a good accordance is found.
Fig. 6 ICW-wing layup optimization sample: optimization for rudder efficiency

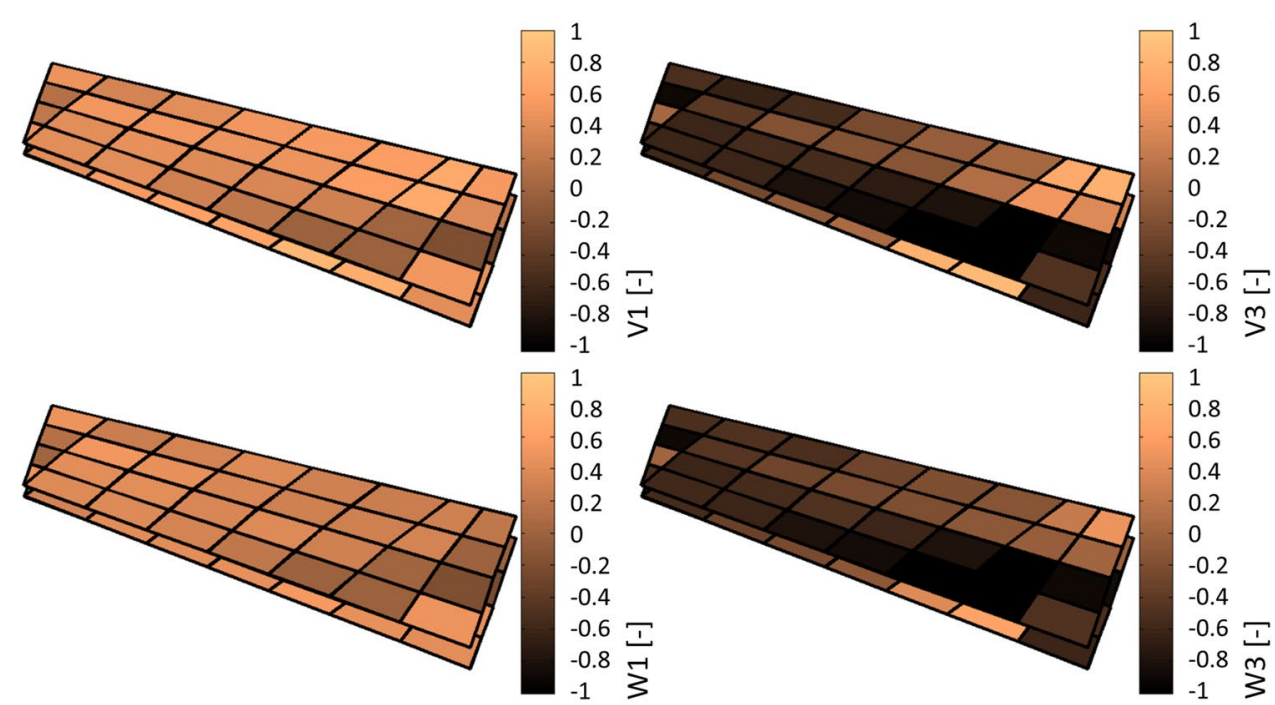




\section{Use of balanced and unbalanced laminates on the XRF1 with aeroelastic constraints}

The first transport aircraft application of the aeroelastic design and tailoring process in the SFWA project was the so-called XRF1, a model of a widebody configuration, which has been distributed by Airbus in the framework of SFWA. The goal was to provide an aircraft model to research institutes which includes structure and aerodynamics data as a base to allow investigations with a model of relevant complexity and behaviour. However, the industrial model turned out to be too complex for a quick variation of stiffness properties needed for the work in the Adaptive Wing work package. It was thus decided to generate a similar, but not identical, parametric aircraft model, see Fig. 7, using the aeroelastic design process described in Sect. 2, and based on the operational parameters provided by Airbus with the XRF1. Part of the model generation was the definition of a representative flight envelope, e.g. cruise and manoeuvre speeds, and altitude.

Several investigations were performed on the XRF1 model. First, a statically and dynamically equivalent shell model of the XRF1 wing was built in the parametric model generator, suitable for subsequent structural adaptations and modifications. The topology followed that of the original XEF1 wing; see Fig. 8. A finite element model with a defined set of thickness and layup parameters was generated, where the parameters were derived from the original
XRF1 wing. A static validation using the application of forces and a comparison of wing deformation between the original XRF1 and the DLR variant was performed, as well as a dynamic validation including non-structural masses which were derived from the XRF1 wing. Finally, a structural optimization of the DLR wing with respect to aeroelastic objectives and constraints, especially weight and control surface efficiency, was performed. The basic DLR model was set up assuming balanced laminates.

In a second step, a study comparing the influence of using balanced and unbalanced laminates on wing mass in the presence of aeroelastic constrains was performed. Aeroelastic constraints include a required aileron efficiency as well as constraints on maximum local wing twist. Two wing designs are compared-a first model consists of standard balanced laminates, a second, otherwise identical, model consists of unbalanced laminates. Both models are optimized for minimum weight under the requirement of varying aileron efficiency and a maximum acceptable wing twist. The laminates remain symmetric, i.e. the matrix $B$ is zero.

Figure 9 shows the discretization of the wing for optimization. The wing is partitioned in design fields spanwise and chordwise, 34 fields per skin, i.e. 68 fields total. 13 NASTRAN design variables are defined per field, resulting in a total of 884 design variables. 486 elements are used per skin, i.e. a total of 972 . The responses taken from the analysis are the weight response (i.e. mass), stress responses from the design fields (based on which strain and buckling failure are computed externally), twist responses of the wing and aileron efficiency response. The objective function is
Fig. 7 XRF1-based model from DLR design loop

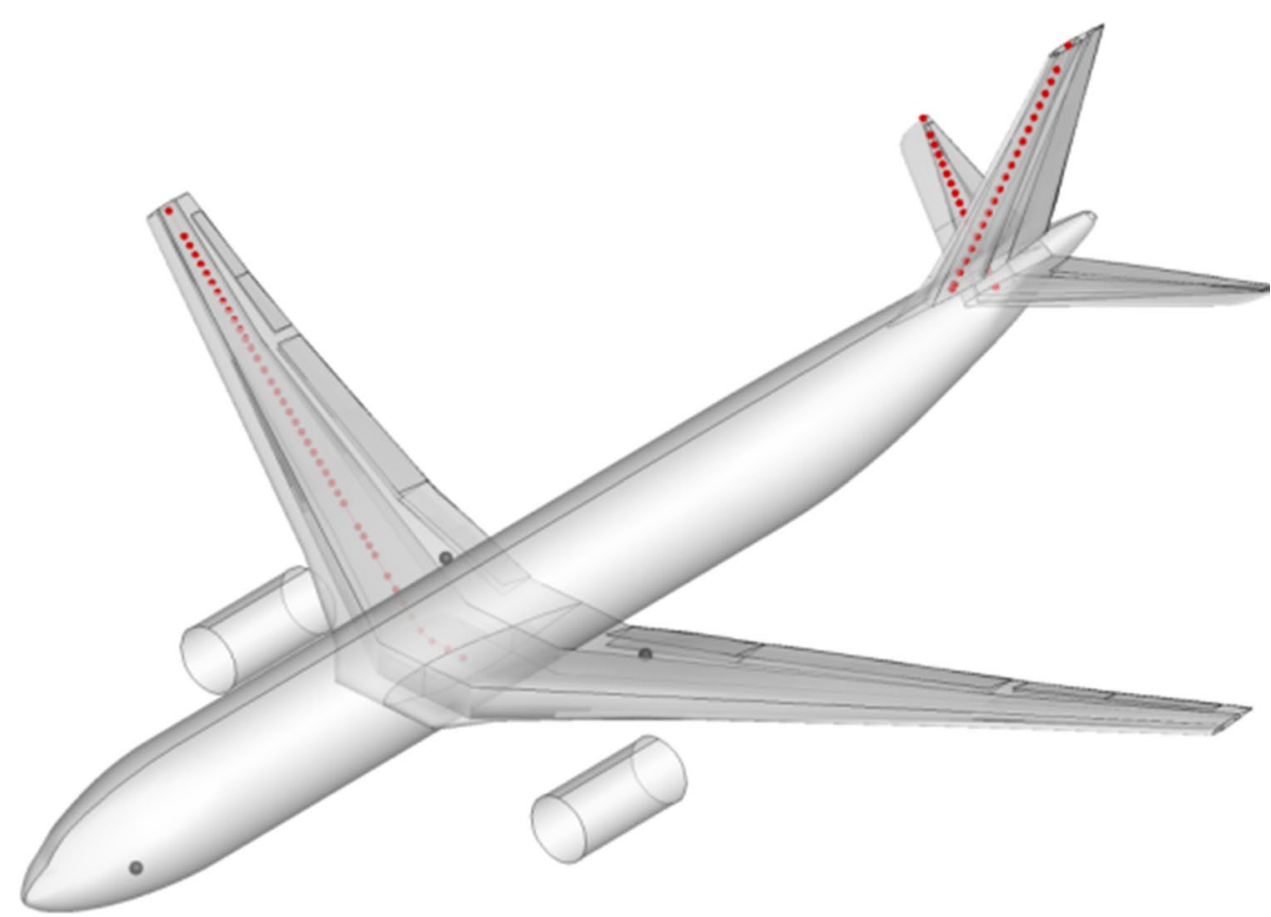


Fig. 8 Topology of DLR variant of XRF1 wing structure

Fig. 9 Design fields of DLR variant of XRF1 wing structure
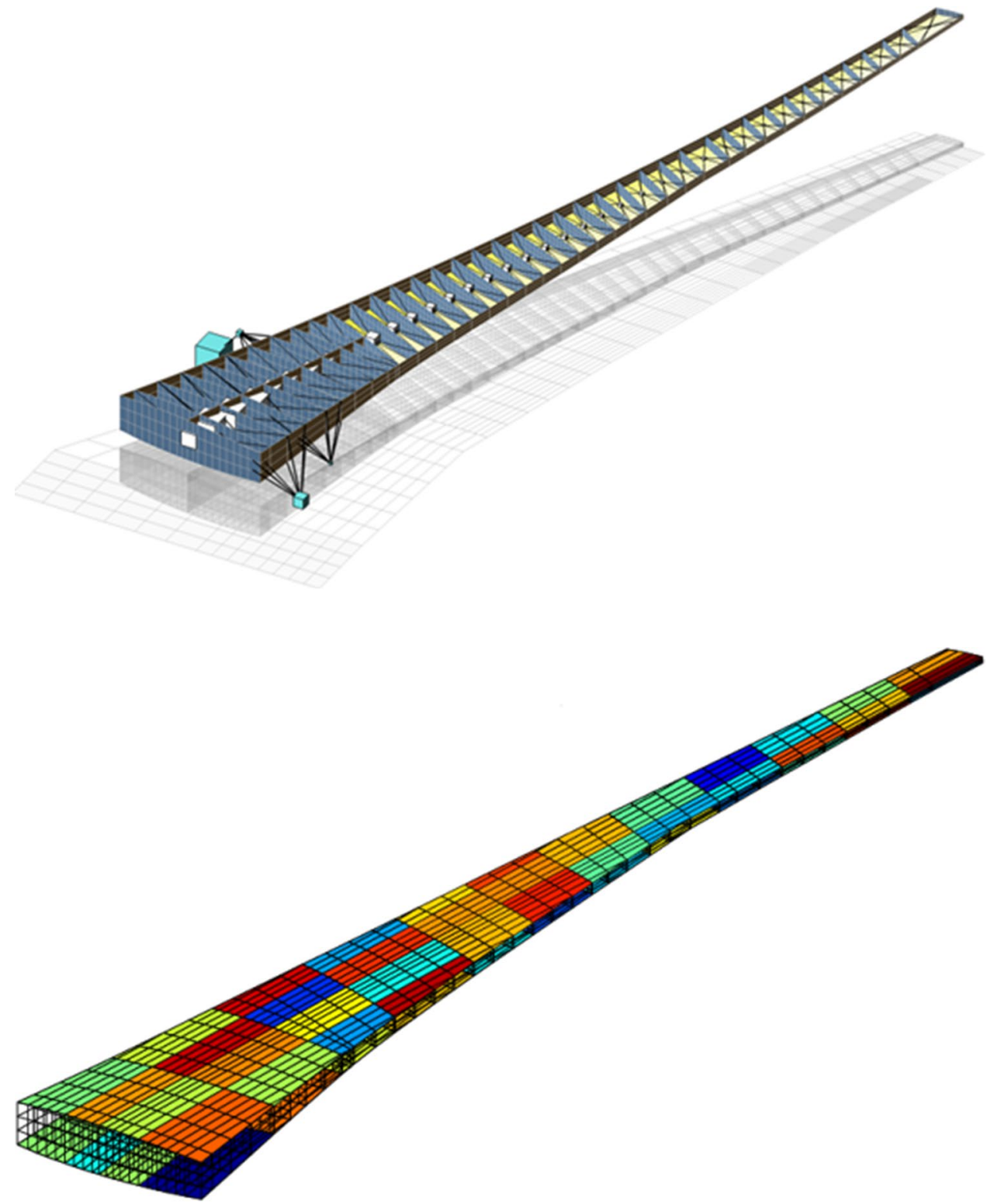

minimum structural mass, under the consideration of the aeroelastic constraints mentioned above.

Seven load cases taken from the assumed operational envelope were selected as wing sizing load cases for the current investigation, i.e. two symmetric pull-up manoeuvres at $n_{z}=2.5$, a symmetric pushdown manoeuvre at $n_{z}=-1$, three rolling cases and one trim case at cruise speed.

Figure 10 shows two typical results for the thickness distribution of the wing, derived from the optimizations result not including the aileron efficiency constraint, Fig. 10, left, and including the constraint, Fig. 10, right. It can be seen well that the optimizer increases wing thickness outboard to reduce wing twist under aileron deflection.

Figure 11 shows a typical stiffness distribution of an optimized wing with unbalanced laminates. Similar to Fig. 3, right, the red curves in Fig. 11 indicate the main stiffness directions in a design field (see [17] for a more in-depth explanation of the visualization of distributed laminate stiffness). It can be seen how the main stiffness direction points backwards on the wing tip, indicating that a pronounced bending torsion coupling, opposing the geometric wash-out effect, is induced by the optimizer to increase the aileron effectiveness and thus fulfil its constraint, noting, however, that this also leads to an increase in inboard loading for highg manoeuvres or gust loads.

To verify whether a sufficiently global optimum of the structural optimization has been reached, the optimization was started from various initial conditions. It could be shown that optimization results are independent from the 

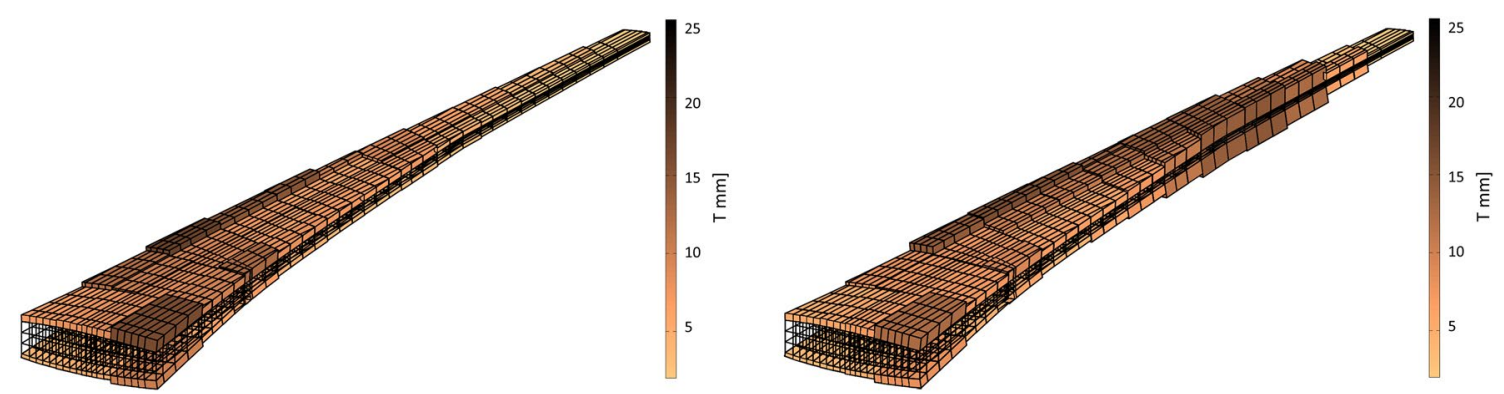

Fig. 10 Typical resulting thickness distribution of laminates after wing optimization; left: aileron constraint not included, right: aileron constraint included

Fig. 11 Typical resulting stiffness distribution of laminates after wing optimization

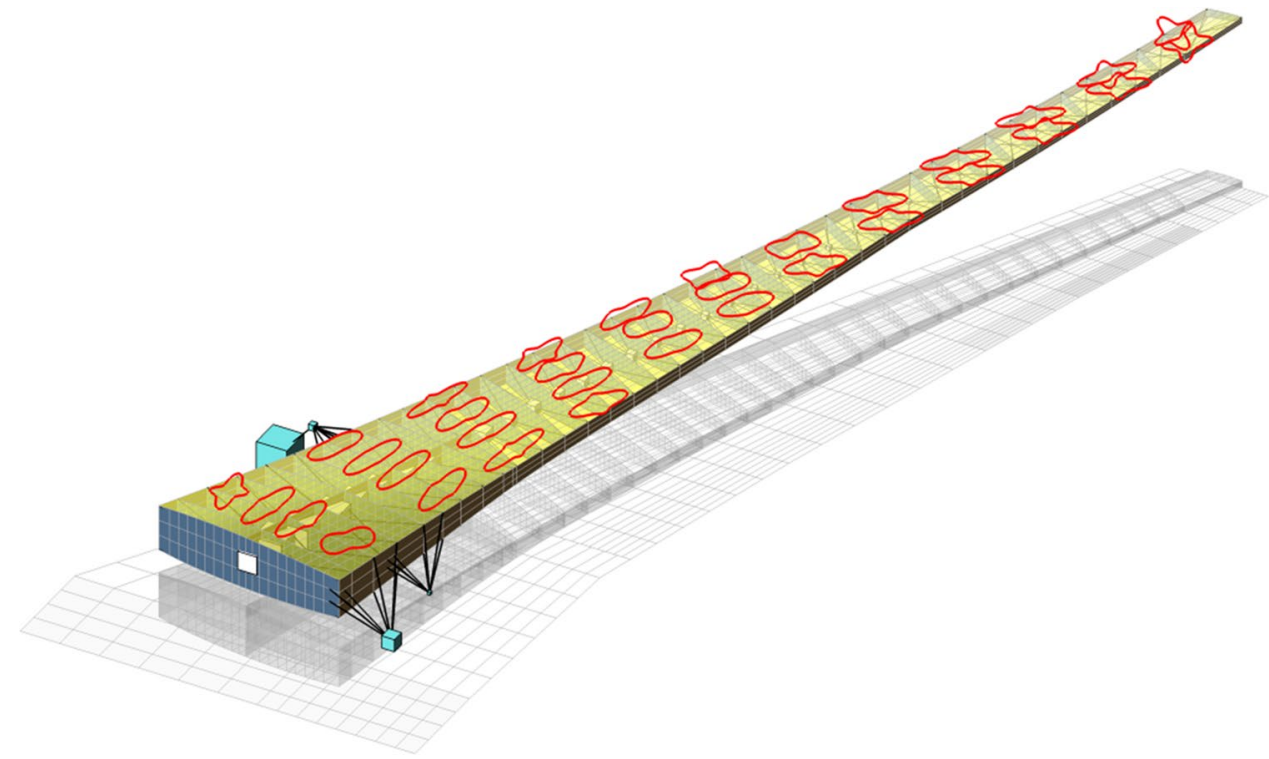

starting point and can clearly be interpreted with respect to the boundary conditions.

Significant differences can be seen for the use of balanced and unbalanced laminates under consideration of aeroelastic constraints, here especially the high speed aileron efficiency. By using balanced laminates, the aeroelastic constraints are mainly met by an increase of torsional stiffness in the outer wing, resulting effectively in a mass increase because of increasing material thickness. In case of unbalanced laminates, the bending torsion coupling on the outer wing becomes more pronounced, the material thickness remains thinner and the wing mass remains lower, overcompensating the necessary additional material needed for the increase in torsional stiffness on the outer wing.

For a wing with balanced laminates, the mass increase due to the introduction of the aeroelastic constraints is about $50 \%$. This trend is generally well known, of course, and a common solution is the use of split ailerons on production aircraft to secure the required aileron efficiency at high speeds. However, it is interesting to see that the mass penalty for a wing with unbalanced laminates is $10 \%$ smaller than the penalty of the design with balanced laminates.

As a consequence of the work, it can be shown that aeroelastic constraints are essential for adequate and meaningful optimization of wing structures. A requirement on aileron efficiency in particular greatly affects the structural weight; the effect could be quantified for different requirements. Second, the investigations prove that the introduction of unbalanced laminates has a great potential for weight reduction and loads reduction. As the XRF1 model is based on an Airbus design, numerical values for the optimization results of the XRF1 application example used in the project cannot be given in the article. However, an identical approach was used for a generic forward-swept wing design, resulting in similar observations, where the results are published in [29]. 


\section{CFD-based corrections for aeroelastic tailoring of the new short range aircraft configuration}

The so-called new short range (NSR) aircraft is a configuration developed in the SFWA project by Airbus for global design studies. For the use in the Adaptive Wing work package, Airbus supplied a geometric database of a half-model consisting of wing and fuselage (Fig. 12) [30]. The half-span of the model is approximately $18 \mathrm{~m}$, and the fuselage length is approximately $40 \mathrm{~m}$. In the Adaptive Wing work package, a representative structure for the design is developed.

Using the aeroelastic design process, an initial wing design is defined which is then sized using the aeroelastic tailoring process described above. Figure 13 shows the layout of the wing box of the NSR wing. The engine is assumed to be located under the wing similar to the current A320 layout, rigidly attached to the wing structure as a point mass. The leading edge and trailing edge components of the wing as well as the systems and the landing gear are considered as mass points.

The wing is sized using a number of selected static load cases. The load analysis as well as the generation of sensitivities necessary for optimization is performed using NASTRAN. In Fig. 14, the colours indicate the design field distribution of the NSR wing. Properties of neighbouring shell elements (sharing the same colour) were combined as design variables to reduce the total number of variables changed by the optimizer.

In the studies following the design, the goal of the analysis was the investigation of the influence of aileron effectiveness constraint on minimized wing skin mass. Calculations were performed for a set of required aileron effectiveness constraints of $\eta_{\text {ail }} \geq 0.00$ and $\eta_{\text {ail }} \geq 0.03$. The aileron efficiency is expressed in terms of the so-called "helix angle", the angle between flight path velocity $v_{\infty}$ and the wing tip velocity $p \cdot s$, see Fig. 15 . The wing rotates with a roll rate of $p$ (taken from the NASTRAN analysis), and $s$ is the semispan. The aileron effectiveness is equal to the arc tangent of the helix angle for unit aileron deflection.

The load cases which were regarded included manoeuvre load cases of $n_{z}=-1$ and 2.5 at a Mach number of 0.597 and altitudes of $0 \mathrm{~m}$ and $6700 \mathrm{~m}$. Load cases relevant to aileron effectiveness were defined at several Mach numbers and altitudes, as well as for several mass cases.

The optimization model contained parameters representing the structural responses (e.g. mass, strain failure, buckling failure), as well as the aeroelastic responses, i.e.

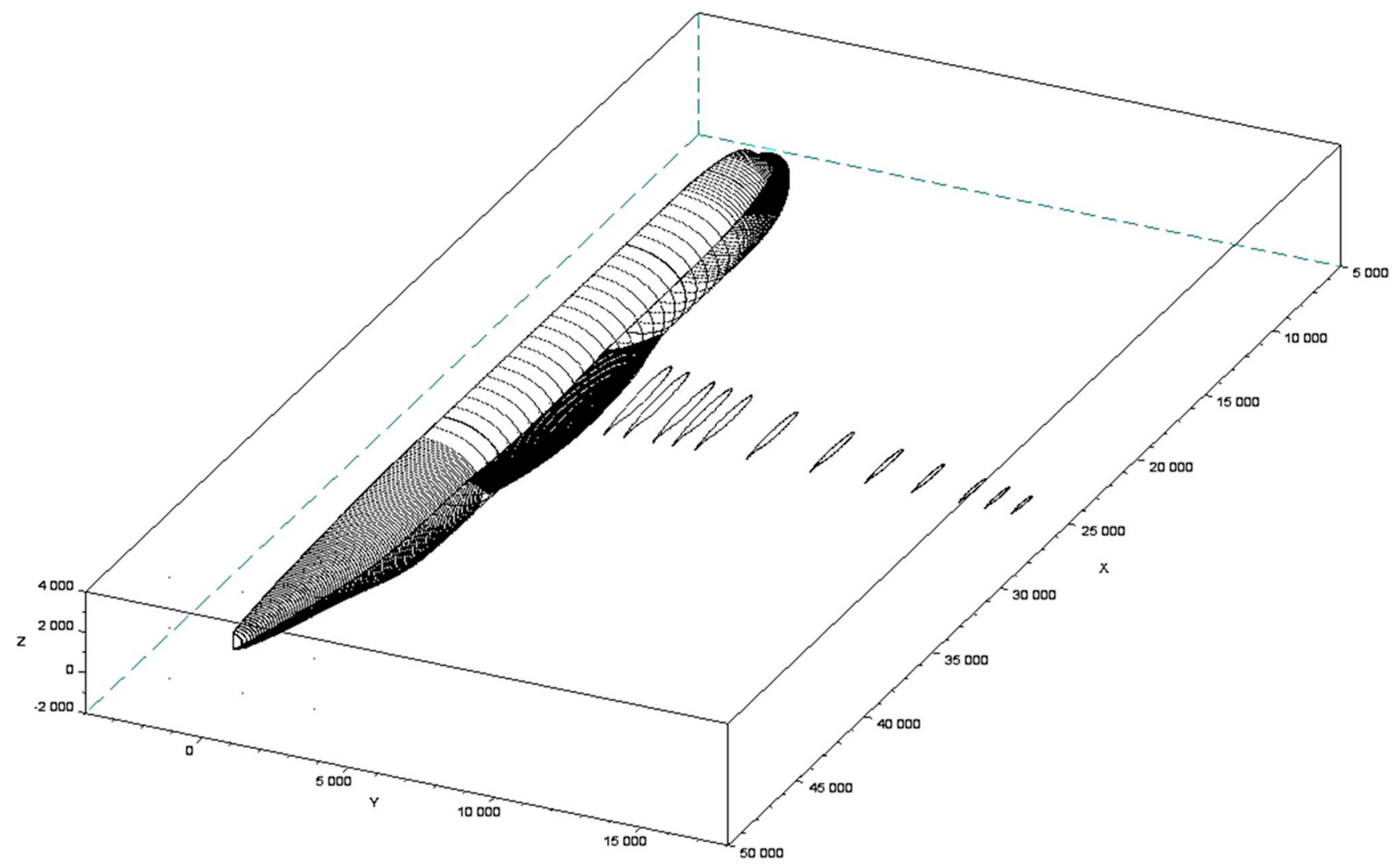

Fig. 12 New short range (NSR) aircraft geometric data supplied by Airbus 


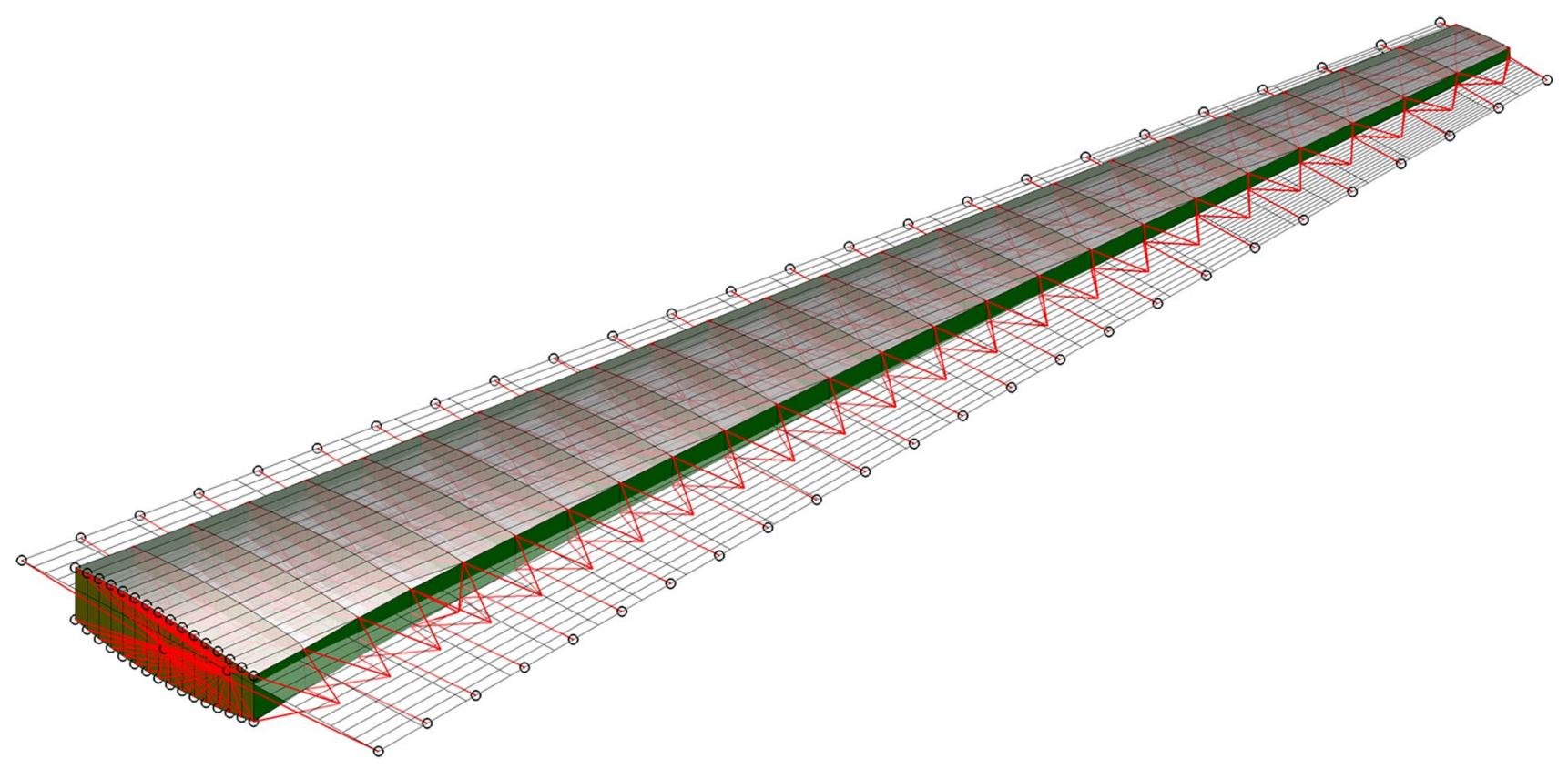

Fig. 13 Structural layout of the NSR wing box-coupling points for aerostructure coupling

Fig. 14 Design fields of NSR wing

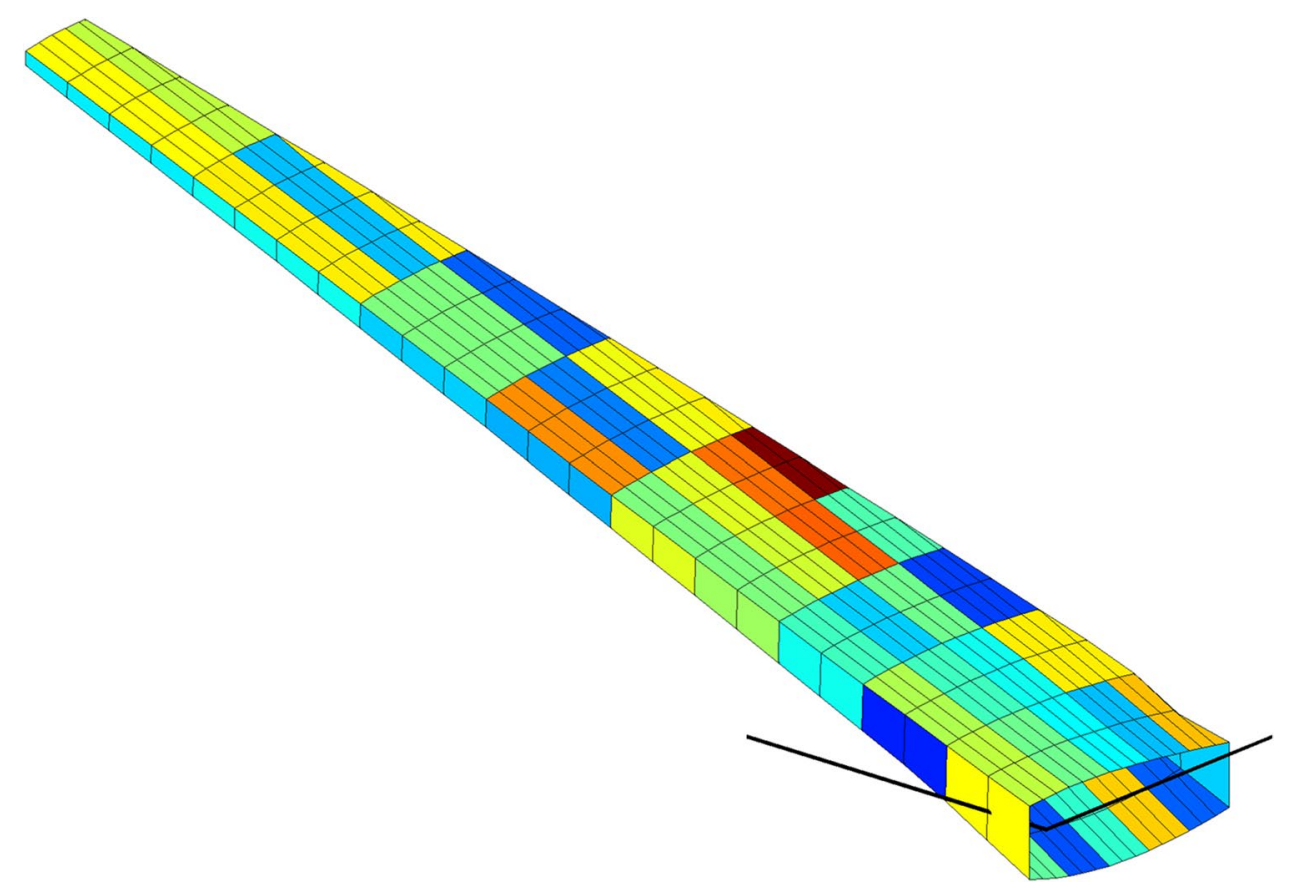

aileron effectiveness, divergence, and twist. It showed that divergence and twist constraints were not active during the optimization. The design variables consisted of membrane and bending stiffness matrix $A$ and $D$, and thickness $h$. Each design field comprises a unique set of design variables $A, D, h$. A number of 68 design fields in upper and lower skin were defined, 18 design fields in the spars, see above in Fig. 14.
The approach includes the consideration of an aero load correction to improve the aerodynamic quality of the NASTRAN internal DLM by means of a higher order CFD method; see Figs. 16 and 17 below. For the CFD calculations, the DLR TAU code was used, see [31]. For the current study, only CFD calculations for symmetric manoeuvres were included, i.e. the calculation of aileron effectiveness according to Fig. 15 was determined with DLM only. 
Fig. 15 Definition of the helix angle

Fig. 16 Low Ma-number: good agreement between DLM and CFD aerodynamics
Fig. 17 High Ma-number: aero load correction of DLM forces with CFD results
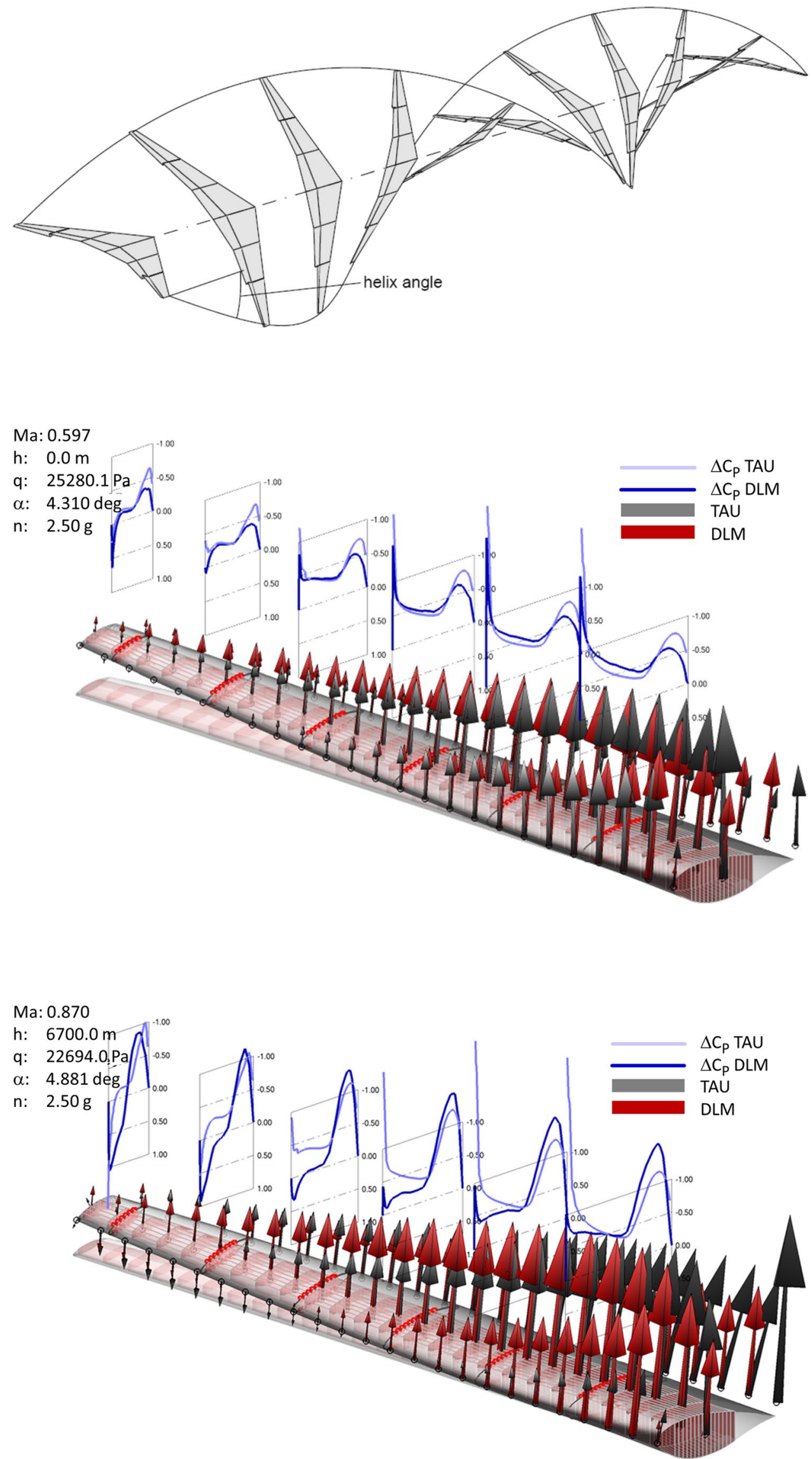
Details on the modelling and the analysis results for a forward swept, but in terms of dimensions similar wing, can be found in [32].

As a sample result it was found that increasing the aileron effectiveness constraint from $\eta_{\text {ail }} \geq 0.00$ (no reversal) to $\eta_{\text {ail }} \geq 0.03$ results in a weight increase of wing skins and spars of approximately $11 \%$.

\section{Assessment of load control concepts with respect to fatigue}

\subsection{Load control design and fatigue analysis}

\subsubsection{Assessment criteria}

The present investigations focus on a methodology for the evaluation of load control concepts with respect to their potential for a reduction of structural weight. Fatigue-relevant loads are sizing for a number of structural components. A decrease in static loads or low-frequency loads should not lead to higher fatigue-relevant loads on those components. Even if the implementation of load control concepts leads to less severe loading of structural components whose mass should or cannot be reduced, the benefit of the load control concept could alternatively be formulated, e.g. in terms of longer maintenance intervals and a resulting reduction in operating costs. The effect of active or passive measures to reduce dynamic loads on fatigue has thus to be taken into consideration.

\subsubsection{Assessment methodology}

The purpose of load control concepts is to change the interaction of the aircraft with the airflow. It is therefore liable to change many aspects of aircraft loading from the overall flight mechanics to the distribution of loads or stresses among structural members. This holds true for active as well as passive load control.

To assess the overall potential for weight reduction available through the implementation of load control concepts it is therefore necessary to use computational methods modelling these mutually interactive effects. Furthermore, the level of detail of the analyses needs to be adaptable to the stage of aircraft design they are used for.

Methodologies with these features have been available in SFWA, so the wing and aircraft design process described in the sections above, based on ModGen and NASTRAN. A finite element (FE) model of the aircraft is subjected to modal reduction and transferred to the MATLAB Simulink environment. Additional submodels for propulsion, gravity, airflow, etc. are added so various operating conditions and loads can be simulated based on the reduced aircraft model. Among the results are load-time histories at certain predefined monitoring stations. In preliminary development stages, submodels may be represented by lower order formulations than in later high-fidelity computations. Thus, computational cost can be offset against the accuracy of results depending on the level of detail of the current design phase. Also, additional submodels can be added in a modular fashion.

In a first step towards an evaluation of load control, baseline analyses are conducted for the relevant load cases without load control. The resulting load-time histories at the monitoring stations are then subjected to a fatigue evaluation consisting of rainflow-counting, mean-value transformation, and damage accumulation, see Fig. 18. In early design phases, generic stress-cycle (so-called SN- or Wöhler-) curves could be used to obtain a virtual damage sum.

In a second step, the load control concept is incorporated into the aircraft model. In case of passive load control (aeroelastic tailoring), the FE-model would be modified accordingly before being subjected to modal reduction. Aerodynamic simulations are then used to modify the airflow submodel as well. The analysis then proceeds as before. Active load control systems would result in an additional submodel including their actuators and control laws. Additional aerodynamic simulations can be used to incorporate the aerodynamic effect of the load control system into the airflow submodel or a separate submodel. In any case, the load-time histories at the monitoring stations will be obtained for the relevant load cases as before and then subjected to the fatigue evaluation mentioned above.

A comparison between the virtual damage sums with and without load control will then be used to evaluate the effect of the load control concept. Depending on the level of

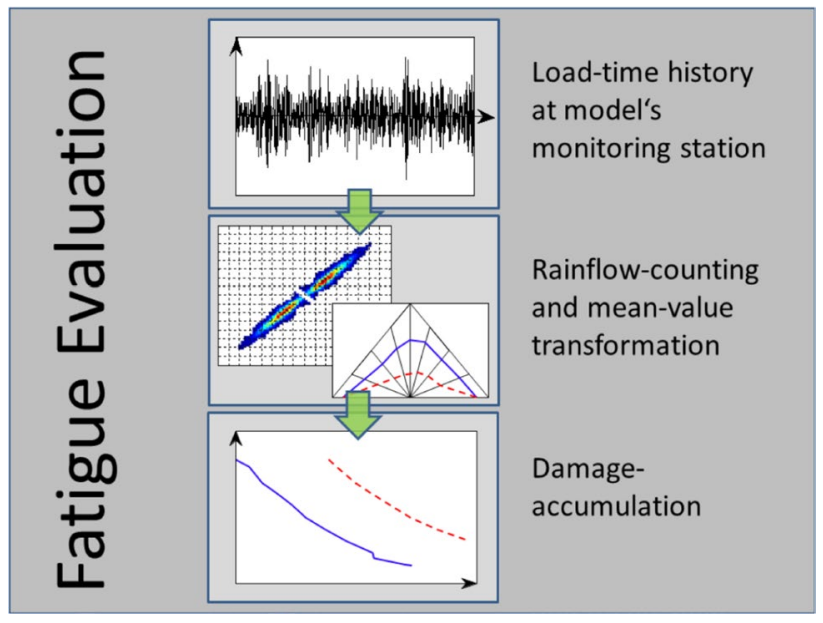

Fig. 18 Fatigue evaluation for load-time histories at aircraft model wing monitoring stations 
detail, this can be expressed in a comparison of preliminary weights of structural members, if possible. The approach presented here is documented in [33]. The work performed on the NSR aircraft presented in the following section was performed on the basis of the suggested approach.

\subsection{Investigation of the influence of aeroelastic tailoring on fatigue loads}

An investigation of the influence of aeroelastic tailoring on fatigue was performed as a cooperation study between the DLR Institute of Aeroelasticity and the Fraunhofer Institute for Structural Durability and System Reliability.

Analysis of fatigue flight loads is usually based on turbulence spectra for trimmed flight conditions. The assumption is that continuous turbulence occurs as a spatially varying stochastic process. The spectra are defined as power spectral density (PSD) functions. Well-known examples for turbulence spectra are the von Kármán wind turbulence model and the Dryden wind turbulence model. When a wing structure is optimized with a heavy focus on load reduction, its natural frequencies and mode shapes might differ considerably from a standard wing design. The same is true for the use of unbalanced laminates in comparison to the use of balanced laminates. The frequency response of the wing when excited by atmospheric turbulence will thus be affected. Consequently, an activity in the SFWA work package Adaptive Wing was an investigation whether a passive wing design, tailored for minimum loads, would influence the fatigue behaviour of the resulting wing with respect to a standard layout.

In this study the new short range (NSR) configuration described in Sect. 4 is used. The two wing designs presented above, with aileron effectiveness constraints of $\eta_{\text {ail }} \geq 0.00$ ("wing 1") and $\eta_{\text {ail }} \geq 0.03$ ("wing 2"), were compared. On the wing, so-called "monitoring stations", i.e. nodes on the wing surface, are defined for which the analysis is performed. First, the transfer functions for the gust input on the response of the two wings at the monitoring station, here a vertical load, are calculated in NASTRAN. The transfer functions are exported, the further process steps are performed in a MATLAB environment. Second, the continuous turbulence input is defined as a PSD function. For the study, the input is a standard turbulence spectrum at moderate excitation for cruise flight conditions. Next, for the given transfer functions, PSD load analyses using the given turbulence spectrum are performed. The results are PSD representations of the wing response at the selected monitoring points, see for example Fig. 19, for the vertical load at the wing root of the wing with $\eta_{\text {ail }} \geq 0.03$, i.e. wing 2 . In the plot, the dotted red lines indicate the natural frequencies of the wing.

Fatigue analyses usually work based on the evaluation of time series. Thus, an equivalent time history for the PSD
Fig. 19 Results for stochastic gust analysis: PSD of the vertical load on the wing root; red lines: wing natural frequencies

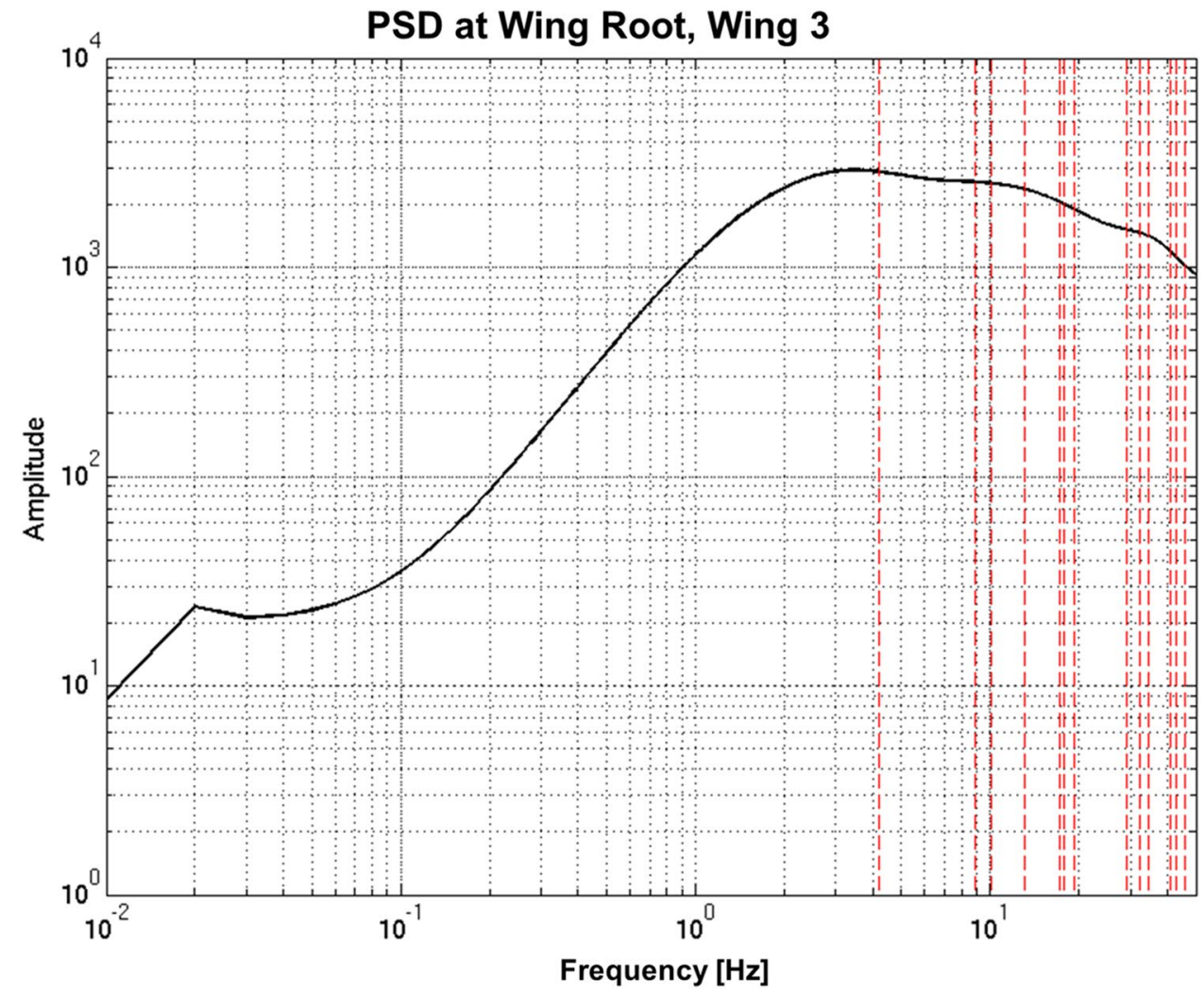


Fig. 20 Equivalent time series for load history at wing root

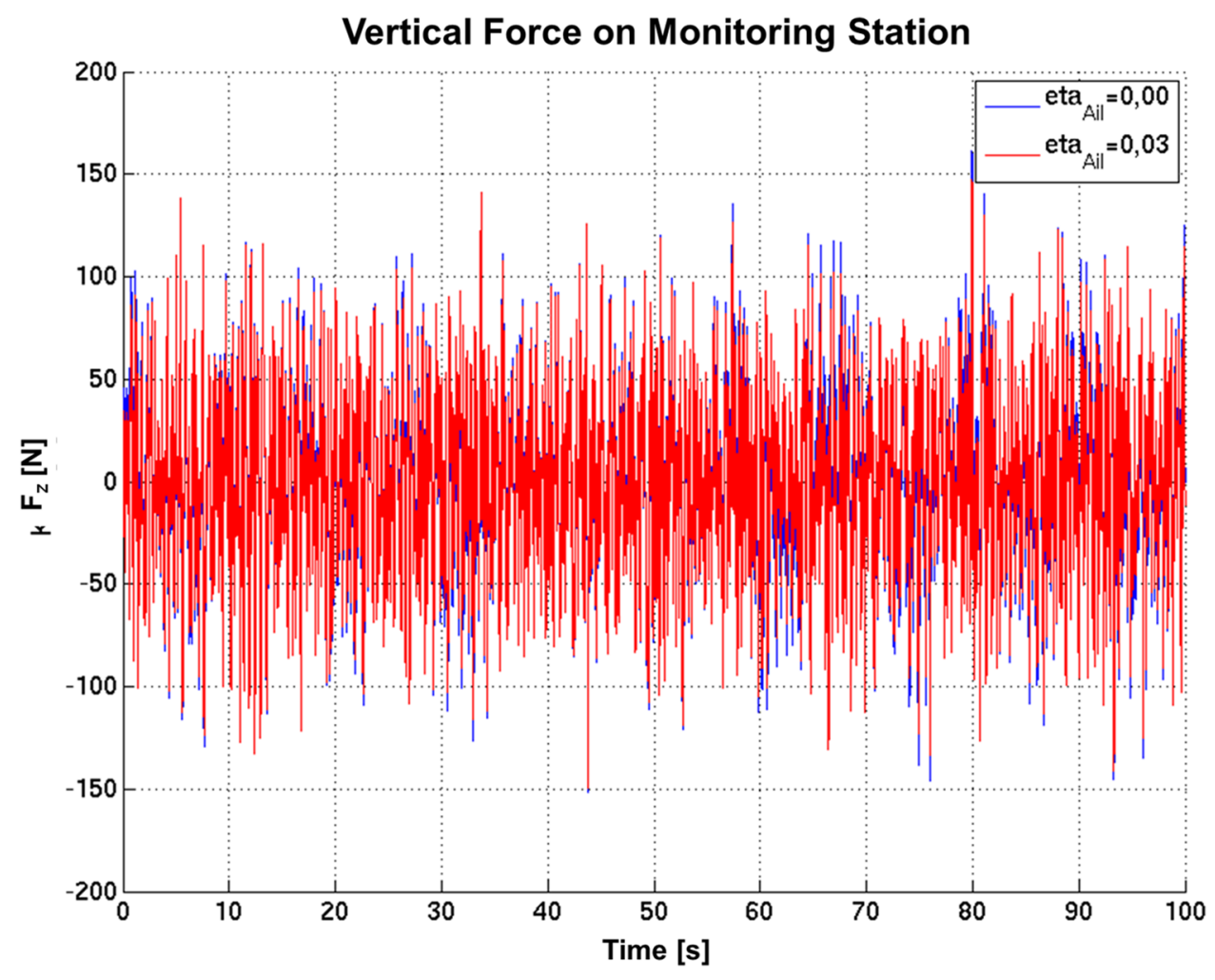

results was generated for each monitoring point; see Fig. 20 for loads at the wing root.

Finally, exceedance curves for load levels were created. Here, discretized load levels are plotted over the number of crossings of those load levels (i.e. exceedance). Those plots will then be the basis for a fatigue evaluation of the wing concepts. The results for two wing designs are presented in Fig. 21. For the given excitation, the wings show very similar behaviour for higher-amplitude responses with low occurrence. For a higher number of exceedance, wing
Fig. 21 Exceedance curve for load levels

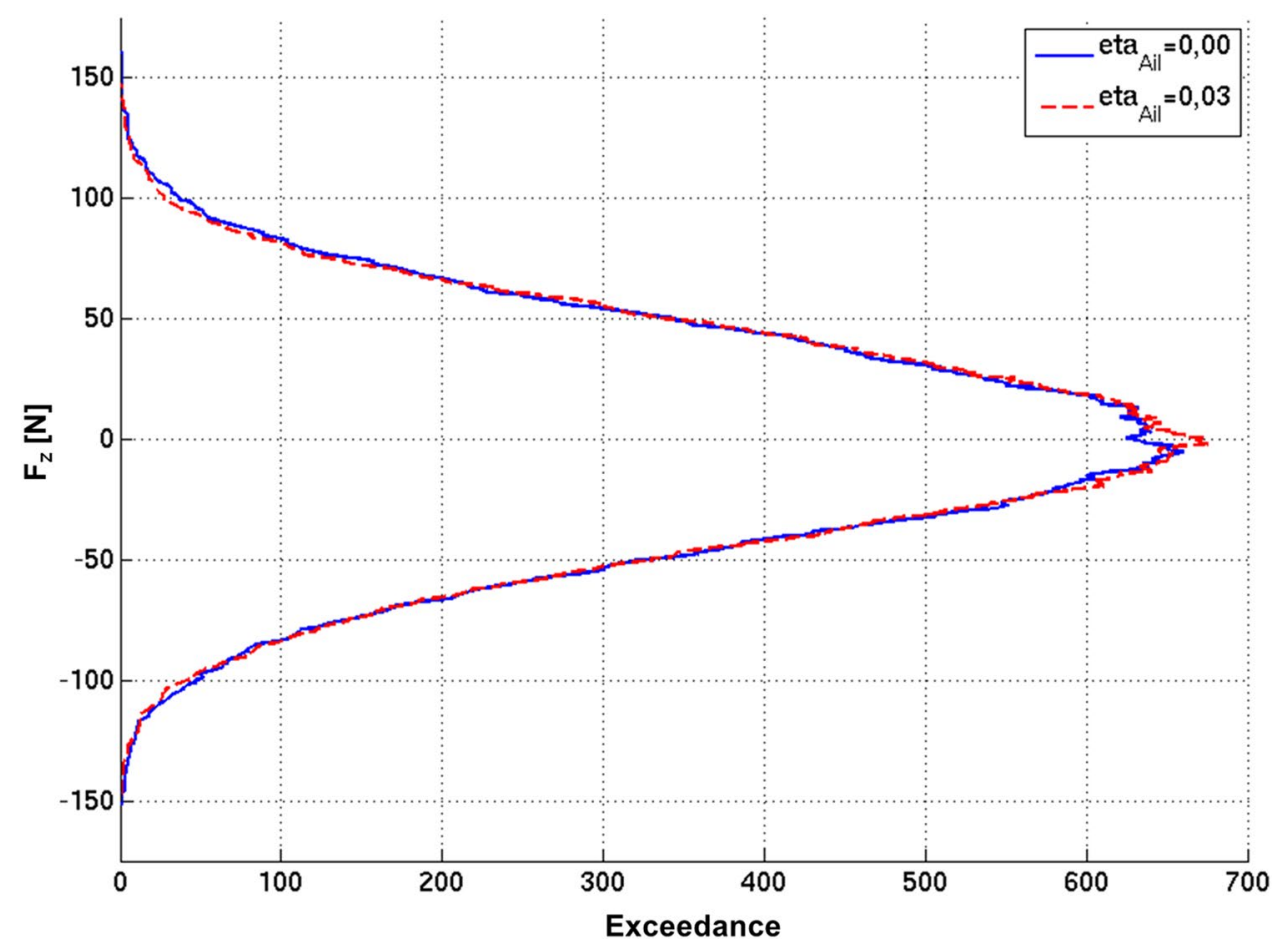


2 shows higher responses. This might be due to the fact that the wing has a higher torsional stiffness to maintain the required aileron efficiency. Summarizing the results of the study, the process showed its capability for the required investigations, however, for the given wing designs, no great difference in fatigue behaviour would probably be expected.

It could thus be shown that the aeroelastic design and tailoring process is capable of generating the necessary input for a subsequent fatigue analysis which can than evaluate whether a wing design optimized for load reduction suffers potential disadvantages when regarding fatigue. However, such a final evaluation is heavily based on the selected material, and thus outside the scope of the activities performed in the Adaptive Wing work package.

\section{Summary and outlook}

In the CleanSky "Smart Fixed Wing Aircraft" project, a multi-fidelity wing design process based on parametric modelling and aeroelastic tailoring has been developed. The process could be demonstrated on a long range and a short range aircraft configuration, with investigations on the use of unbalanced laminates in structural optimization, the influence of the aileron efficiency on wing mass, the introduction of CFD-based aerodynamics in the process, and an important step towards the assessment of the influence of passive load control on fatigue. The wide field of work could only be covered because of the fruitful cooperation of the partners whose expertise was complementary.

Next steps to be taken are the integration of the aeroelastic tailoring process in a comprehensive loads loop, in order to increase the number of relevant load cases in the optimization. This effort was started by DLR [1, 34]. Furthermore, the current optimization is based is load cases without the application of active load control. Thus, a combined optimization of structure and control parameters (sometimes termed "aeroservoelastic tailoring") is an important further development. Finally, the investigations of the relevance of aeroelastic tailoring on fatigue will be pursued by the partners.

Acknowledgements The authors would like to thank the Clean Sky Joint Undertaking and the European Union for the support of SFWAITD which has been funded within the scope of the Seventh Framework Programme for Research and Technology by the European Commission through the Grant Agreement CSJU-GAM-SFWA-2008-001.

Open Access This article is distributed under the terms of the Creative Commons Attribution 4.0 International License (http://creativeco mmons.org/licenses/by/4.0/), which permits unrestricted use, distribution, and reproduction in any medium, provided you give appropriate credit to the original author(s) and the source, provide a link to the Creative Commons license, and indicate if changes were made.

\section{References}

1. Bramsiepe, K.R.B., Handojo, V.H., Meddaikar, M.Y., Schulze, M., Klimmek, T.: Loads and structural optimisation process for composite long range transport aircraft configuration. In: AIAA Aviation and Aeronautics Forum and Exposition (AIAA AVIATION 2018). 25-29 June 2018, Atlanta, Georgia, USA, submitted May 2018 (2018)

2. Kroll, N., Abu-Zurayk, M., Dimitrov, D., Franz, T., Führer, T., Gerhold, T., Görtz, S., Heinrich, R., Ilic, C., Jepsen, J., Jägersküpper, J., Kruse, M., Krumbein, A., Langer, S., Liu, D., Liepelt, R., Reimer, L., Ritter, M., Schwöppe, A., Scherer, J., Spiering, F., Thormann, R., Togiti, V., Vollmer, D., Wendisch, J.-H.: DLR project Digital-X: towards virtual aircraft design and flight testing based on high-fidelity methods. CEAS Aeronaut. J. 7(1), 3-27 (2015)

3. Regan, C.D., Jutte, C.V.: Survey of applications of active control technology for gust alleviation and new challenges for lighterweight aircraft. NASA/TM-2012-216008, Dryden Flight Research Center, Edwards (2012)

4. Fezans, N., Joos,, H.-D., Deiler, C.: Gust load alleviation for a long-range aircraft with and without anticipation. CEAS Aeronaut. J. (2019) (special issue on SFWA, accepted)

5. Pendleton, E.W., Bessette, D., Field, P.B., Miller, G.D., Griffin, K.E.: Active aeroelastic wing flight research program: technical program and model analytical development. J. Aircr. 37(4), 554-561 (2000). https://doi.org/10.2514/2.2654

6. Cheung, R.C., Rezgui, D., Cooper, J.E., Wilson, T.: Testing of folding wing-tip for gust load alleviation in high aspect ratio wing. In: AIAA Scitech 2019 Forum, AIAA SciTech Forum, (AIAA 2019-1863) (2019). https://doi.org/10.2514/6.2019-1863

7. Scott, R.C., Allen, T., Castelluccio, M., Sexton, B., Claggett, S., Dykman, J.R., Funk, C., Coulson, D., Bartels, R.E.: Aeroservoelastic wind-tunnel test of the SUGAR truss braced wing wind-tunnel model. In: 56th AIAA/ASCE/AHS/ASC Structures, Structural Dynamics, and Materials Conference, AIAA SciTech Forum, (AIAA 2015-1172) (2015). https://doi. org/10.2514/6.2015-1172

8. Livne, E.: Aircraft active flutter suppression: state of the art and technology maturation needs. J. Aircr. 55(1), 2018 (2018). https ://doi.org/10.2514/1.C034442

9. Starnes Jr., J.H., Haftka, R.T.: Preliminary design of composite wings for buckling, strength, and displacement constraints. J. Aircr. 16(8), 564-570 (1979)

10. Hollowell, S.J., Dungundji, J.: Aeroelastic flutter and divergence of stiffness coupled, graphite epoxy cantilevered plates. J. Aircr. 21(1), 69-76 (1984)

11. Shirk, M.H., Hertz, T.J., Weisshaar, T.A.: Aeroelastic tailoringtheory, practice, and promise. J. Aircr. 23(1), 6-18 (1986)

12. Vanderplaats, G.N., Weisshaar, T.A.: Optimum design of composite structures. Int. J. Numer. Methods Eng. 27(2), 437-448 (1989)

13. Leon, D.M., Souza, C.E., Fonseca, J.S.O., Silva, R.G.A.: Aeroelastic tailoring using fiber orientation and topology optimization. Struct. Multidiscip. Optim. 46(5), 663-677 (2012)

14. Kameyama, M., Fukunaga, H.: Optimum design of composite plate wings for aeroelastic characteristics using lamination parameters. Comput. Struct. 85(3-4), 213-224 (2007)

15. Abdalla, M.M., De Breuker, R., Gürdal, Z.: Aeroelastic tailoring of variable-stiffness slender wings for minimum compliance. In: International Forum on Aeroelasticity and Structural Dynamics (IFASD). IF-117. Stockholm, 2007 (1997)

16. Liu, D., Toropov, V.V.: A lamination parameter-based strategy for solving an integer-continuous problem arising in composite optimization. Comput. Struct. 128(2013), 170-174 (2013) 
17. Dillinger, J.: Static aeroelastic optimization of composite wings with variable stiffness laminates. Dissertation. DLR-Forschungsbericht. 2015-05. (2015) https://elib.dlr.de/94538/1/Thesis.pdf. Accessed 30 Apr 2019

18. European Commission (Ed): Technology readiness levels (TRL). European Commission, G. Technology readiness levels (TRL), HORIZON 2020—WORK PROGRAMME 2014-2015, General Annexes, Extract from Part 19-Commission Decision C (2014)

19. Dillinger, J., Klimmek, T., Abdalla, M.M., Gürdal, Z.: Stiffness optimization of composite wings with aeroelastic constraints. J. Aircr. 50(4), 1159-1168 (2013). (AIAA. ISSN 0021-8669)

20. De Breuker, R., Abdalla, M.M., Werter, N.P.M., Vandewaeter, L., Ferede, E.A., Dillinger, J.K.S. \& Krüger, W.R.: An aeroelastic multi-fidelity approach for aeroelastic tailoring. In: Proceedings of International Forum on Aeroelasticity and Structural Dynamics, IFASD 2013. London (2013)

21. Klimmek, T.: Parameterization of topology and geometry for the multidisciplinary optimization of wing structures. In: Proceedings "CEAS 2009". CEAS 2009-European Air and Space Conference, 26-29 October 2009, Manchester (2009)

22. Klimmek, T.: Parametric set-up of a structural model for FERMAT configuration aeroelastic and loads analysis. J. Aeroelast. Struct. Dyn. 3(2), 31-49 (2014)

23. Krüger, W.R., Klimmek, T., Liepelt, R., et al.: Design and aeroelastic assessment of a forward-swept wing aircraft. CEAS Aeronaut. J. 5, 419 (2014). https://doi.org/10.1007/s13272-014-0117-0

24. MSC.NASTRAN. http://www.mscsoftware.com/product/mscnastran. Accessed 24 Jan 2019

25. Werter, N.P.M., De Breuker, R.: Design of a composite forward swept wing using advanced aeroelastic tailoring optimisation methods. In: Morris, A., Gurdal, Z. (eds.) Proceedings of RAeS 3rd Aircraft Structural Design Conference. London (2012)

26. MATLAB: https://www.mathworks.com/products/matlab.html. Accessed 24 Jan 2019

27. Meddaikar, Y.M., Irisarri, F.-X., Abdalla, M.M.: Blended composite optimization combining stacking sequence tables and a modified Shepard's method. In: 11th World Conference on Structural and Multidisciplinary Optimization, 7-12 Jun 2015, Sydney, Australia (2015)
28. Tischler, V., Venkayya, V., Eastep, F., Bharatram, G.: Design interfaces and data transfer issues in multidisciplinary design. In: Proceedings of 6th AIAA/NASA/ISSMO Symposium on Multidisciplinary Analysis and Optimization, AIAA-96-4125-CP, pp 1212-1222. AIAA, Bellevue (1996)

29. Johannes, J., Abdalla, M.M., Klimmek, T., Gürdal, Z.: Static aeroelastic stiffness optimization and investigation of forward swept composite wings. In: 10th World Congress on Structural and Multidisciplinary Optimization, 19-24 May 2013, Orlando, Florida, USA (2013)

30. Krüger, W.R., Dillinger, J., De Breuker, R., Reyes, M., Haydn, K.: Adaptive wing: investigations of passive wing technologies for loads reduction in the CleanSky Smart Fixed Wing Aircraft (SFWA) project. Greener Aviation, 2016, Paper ID 122, Brussels (2016)

31. Schwamborn, D., Gerhold, T., Heinrich, R.: The DLR TAU-Code: recent applications in research and industry. In: ECCOMAS CFD Conference, Egmond aan Zee (2006)

32. Dillinger, J., Abdalla, M.M., Meddaikar, Y.M., Klimmek, T.: Static aeroelastic stiffness optimization of a forward swept composite wing with CFD corrected aero loads. CEAS Aeronaut. J. (2019) (special issue on SFWA, accepted)

33. Kraus, K., Mayer, D., Herold S., Büter, A.: Online processing for structural health assessment. In: 13th Mechatronics Forum International Conference. Linz, Austria, September 17-19 (2012)

34. Thomas, K., Ohme, P., Ciampa, P.D., Handojo, V.: Aircraft loads - an important task from pre-design to loads flight aircraft loads flight testing. In: Deutscher Luft- und Raumfahrtkongress 2016, 13.-15. Sept. 2016, Braunschweig, Deutschland. DocumentID: 420223, urn:nbn:de:101:1-201703036117 (2016)

Publisher's Note Springer Nature remains neutral with regard to jurisdictional claims in published maps and institutional affiliations. 